\title{
Characterization of Global Research Trends and Prospects on Single-Cell Sequencing Technology: Bibliometric Analysis
}

Quan Wang ${ }^{1,2^{*}}$, MD, PhD; Ke-Lu Yang ${ }^{3 *}, \mathrm{MN}$; Zhen Zhang ${ }^{1,2}$, PhD; Zhu Wang ${ }^{4}$, MD, PhD; Chen Li ${ }^{1,2}, \mathrm{BA}^{2} \mathrm{Lun} \mathrm{Li}^{5}$, MD, PhD; Jin-Hui Tian ${ }^{6}$, PhD; Ying-Jiang Ye ${ }^{1,2}$, MD, PhD; Shan Wang ${ }^{1,2}, \mathrm{MD}$, PhD; Ke-Wei Jiang ${ }^{1,2^{*}}$, MD

${ }^{1}$ Department of Gastroenterological Surgery, Peking University People's Hospital, Beijing, China

${ }^{2}$ Laboratory of Surgical Oncology, Beijing Key Laboratory of Colorectal Cancer Diagnosis and Treatment Research, Peking University People's Hospital, Beijing, China

${ }^{3}$ Evidence-Based Nursing Center, School of Nursing, Lanzhou University, Lanzhou, China

${ }^{4}$ Department of Gastrointestinal Surgery, Shandong Provincial Hospital Affiliated to Shandong First Medical University, Jinan, China

${ }^{5}$ Department of Breast Surgery, Shanghai Cancer Center, Fudan University, Shanghai, China

${ }^{6}$ Evidence-Based Medicine Center, School of Basic Medical Sciences, Lanzhou University, Lanzhou, China

*these authors contributed equally

Corresponding Author:

Ke-Wei Jiang, MD

Department of Gastroenterological Surgery

Peking University People's Hospital

No.11 Xizhimen South Street, Xicheng District

Beijing, 100044

China

Phone: 8601088326600

Email: jiangkewei@pkuph.edu.cn

\section{Abstract}

Background: As single-cell sequencing technology has been gradually introduced, it is essential to characterize global collaboration networks and map development trends over the past 20 years.

Objective: The aim of this paper was to illustrate collaboration in the field of single-cell sequencing methods and explore key topics and future directions.

Methods: Bibliometric analyses were conducted with CiteSpace and VOSviewer software on publications prior to November 2019 from the Web of Science Core Collection about single-cell sequencing methods.

Results: Ultimately, we identified 2489 records, which were published in 495 journals by 14,202 authors from 1970 institutes in 61 countries. There was a noticeable increase in publications in 2014. The United States and high-income countries in Europe contributed to most of the records included. Harvard University, Stanford University, Karolinska Institutes, Peking University, and the University of Washington were the biggest nodes in every cluster of the collaboration network, and SA Teichmann, JC Marioni, A Regev, and FC Tang were the top-producing authors. Keywords co-occurrence analysis suggested applications in immunology as a developing research trend.

Conclusions: We concluded that the global collaboration network was unformed and that high-income countries contributed more to the rapidly growth of publications of single-cell sequencing technology. Furthermore, the application in immunology might be the next research hotspot and developmental direction.

(J Med Internet Res 2021;23(8):e25789) doi: 10.2196/25789

\section{KEYWORDS}

single-cell sequencing; bibliometric analysis; cancer; cancer genomics; bioinformatics; cancer subtyping; tumor dissociation; tumor microenvironment; precision medicine; immunology; development trends; hotspots; research topics; Web of Science; CiteSpace; VOSviewer; network 


\section{Introduction}

A single cell is regarded as the fundamental unit of an organism. Moreover, there are approximately $10^{14}$ single cells that comprise the complex tissues and organs of Homo sapiens [1]. In order to study genomic or transcriptome information, most published studies to date have collected data by analyzing bulk tissue samples and true genomic information representing the average of millions of cells [2]. Accordingly, because of cell-to-cell variability, traditional sequencing methods only provide the average diversity of cells, instead of obtaining information on entire cellular heterogeneity [3]. When facing the complexity of disease, it is difficult for these averaged data sets to represent cell-to-cell variations; therefore, it is difficult for researchers to identify rare cells, including cancer stem cells, that play a key role in cancer progression. To avoid the weakness and limitations of bulk sequencing technologies, the single-cell method offers a novel possibility that focuses on the single-cell level [4], with detailed and comprehensive studies of individual cells rather than traditional analysis of bulk tissue. The first step of sequencing a single cell, however, involves capturing individual cells; therefore, it is of utmost importance to establish various methods for isolating single cells from abundant populations or rare single cells $(<1 \%)$ from typical populations. Several approaches have been well-established, including mouth pipetting, serial dilution, robotic micromanipulation, flow-assisted cell sorting, microfluidic platforms, and laser-capture microdissection, however, the isolation of rare single cells $(<1 \%)$ is far more challenging [2].

With increasing developments of high-throughput sequencing technologies over the past couple of decades, an increasing number of commercial platforms have been introduced for experimental and clinical applications, and thousands of genomes from numerous species have been sequenced [3]. Researchers now have a wealth of data to explore genomic or transcriptome information. Single-cell sequencing refers to the sequencing of a single-cell genome or transcriptome, to reveal cell population differences and cellular evolutionary changes [5]. Furthermore, these commercial methods interrogate the single-cell genome, transcriptome, and epigenome. For example, since the introduction of the first single-cell RNA-sequencing technique in 2009 [6], single-cell RNA sequencing has become a powerful and useful approach to study individual cell transcriptomes on a large scale [7], similar to the technology of multiomics sequencing [8]. When it comes to the applications of single-cell sequencing techniques, the important role of single-cell sequencing in various fields, including oncology [9], microbiology [10], neurology [11,12], reproduction [13], and immunology [14] has been highlighted. These rapidly developing methods have and will continue to lead to new discoveries in many scientific fields.

Recently, because single-cell sequencing technology has been gradually introduced for clinical applications, there has been an increase in research papers published online on this topic. There are more than 70 related records in this field, published online each month on PubMed, and these are of a variety of publication types. Some papers offered a brief introduction of single-cell sequencing technology [15], whereas others focused on investigating its applications [16]. In some reviews [7,17], the current strengths and disadvantages of single-cell sequencing technology were summarized. Published original articles updated or simplified the algorithms of computational methods [18].

Based on this, it is important for us to better understand and learn more from the developmental trends and novel advancements of single-cell sequencing techniques macroscopically; however, rapidly learning about the current landscape of specific biomedical research is still a challenge. Fortunately, the emergence of bibliometric analysis provides an approach to statistically and quantitatively visualize evidence according to the information in published records in a specific field $[19,20]$, which includes data, such as keywords, citation reports, authors, affiliated countries, institutions, and journals, from a large number of published studies. To the best of our knowledge, no specific study has focused on the characterization of research hotspots, global research collaborations, and developmental trends of single-cell sequencing techniques. To characterize current evidence and establish future research directions, it is essential to perform bibliometric analysis to map global collaboration patterns and developmental trends of published single-cell sequencing methods.

The aims of this bibliometric analysis were to map this research landscape through analysis of the information in published records.

\section{Methods}

\section{Data Source and Search Strategy}

We searched the Web of Science Core Collection (WoSCC) without publication date restrictions on November 12, 2019. We updated the database search on January 29, 2020, to complete data retrieval for the year of 2019; however, only the number of records published annually was updated.

The search was performed using the following keywords and terms: ("single-cell RNA sequencing" OR "scRNA-seq" OR "single-cell RNA-seq" OR "single-cell sequencing" OR "single-cell transcriptomic" OR "single-cell ATAC" OR "single-cell RNA-sequencing" OR "single-cell omics sequencing" OR "scRNA seq"). The search strategy was peer-reviewed and guided by TJH (who has over 10 years of experience as an information specialist). In this study, only publications in English were included; however, there was no restriction on data category.

\section{Inclusion and Exclusion Criteria}

Inclusion criteria were published records, including articles, comments, reviews, letters, and brief introductions on single-cell sequencing techniques. We included the records that, not only focused on the single-cell sequencing technology after the paper of single-cell RNA-sequencing published in 2009 [6], but also, generally used the single-cell sorting methods such as Flow sorting in early time. We excluded duplicates, conference abstracts, and manuscripts in a language other than English, for consistent and accurate information collection from multianalysis results based on published records. Two groups of reviewers (WQ/WZ/JKW and YKL/LL) independently screened the titles and abstracts to select the articles after 
standard selection training. Full-texts were retrieved when necessary. Disagreements were discussed and solved between the 2 groups.

\section{Social Network Map Software}

CiteSpace (version 5.3.R4) was used for social network analysis of developmental dynamics, future trends, hotspots, and key points in scientific literature of a specific topic [21]. Burst detection, to identify keywords and references that appear with an abrupt change in frequency at a certain period, were considered to be hot keywords or references at that point in time. Clustering (or co-citation, ie, both $\mathrm{A}$ and $\mathrm{B}$ are cited by C) analysis of references was also conducted [21]. We used VOSviewer (version 1.6.9; Leiden University) to visualize the collaborations between authors of a list of publications as well as those between countries, institutions, and high frequency keywords [22]. One classification method uses a metric based on the number of co-authored articles, which allowed authors, institutions, countries or keywords to be clustered, where those belonging to the same group cooperated more with each other [23]. In network maps, unequal-size nodes with different colors represent differences in the number or frequency of published records in clusters among the same research topics [21]. Lines between nodes indicate the strength of collaborations (the stronger the collaboration, the thicker the line) [24]. We also used overlay visualization, in which the color of the node represents the average year in which each author, institution, country or keyword was used [25].

Data were saved as Plain Text with Full Record and Cited References in WoSCC and imported into CiteSpace.

\section{Statistical Analysis}

SPSS software (version 22.0; IBM Corp) and Origin (version 2018; OriginLab Corp) were used for data analysis. Continuous variables were presented as mean and standard deviation or median and interquartile range, and categorical variables were expressed using frequencies and percentages.

\section{Results}

\section{Search Results}

A total of 2584 publications were identified from WoSCC. After screening titles and abstracts, duplicates, unrelated topics, and conference abstracts $(n=80)$ or non-English publications $(n=15)$ were excluded. Finally, 2489 studies were included for bibliometric analysis (Figure 1); 2607 was identified as the number of records published.

Figure 1. Record identification and selection.

\section{Keywords and free words search in Web of Science Core Collection $($ WoSCC $)(n=2584)$} searching to November 12, 2019

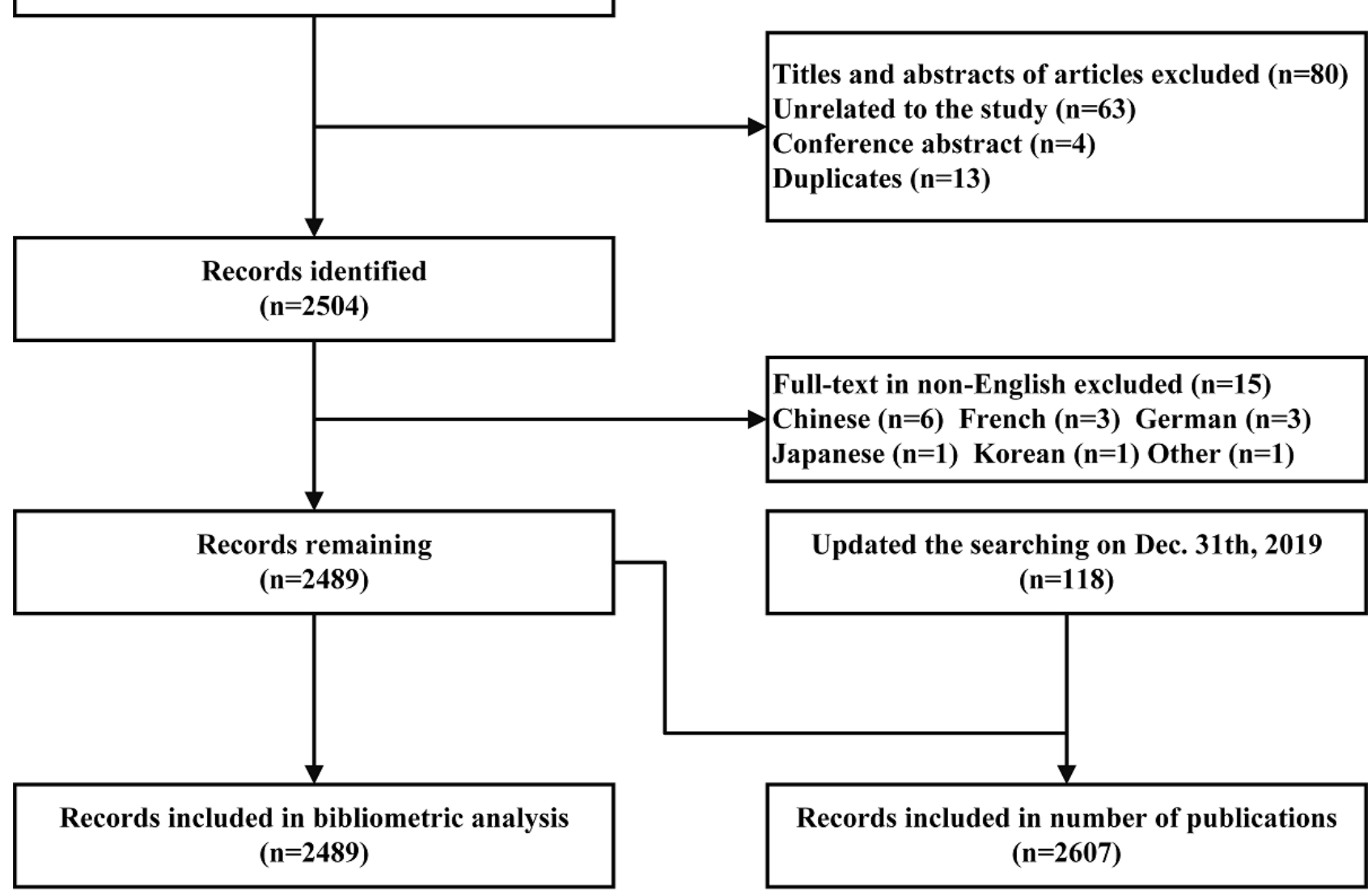




\section{Global Publication Trends}

Papers published over the past of two decades (Table 1 and Table 2) were primarily classified into 7 types. Most papers were original articles $(1858 / 2607,71.27 \%)$, and there were $388 / 2607$ meeting abstracts (14.84\%) and 217/2607 reviews $(8.32 \%)$. Most publication types were articles, meeting abstracts, and reviews, which can greatly reflect the development trends and changes in single-cell sequencing technology. The first publication on single-cell sequencing technology was in 2001 [26], which reported single-cell sequencing of dinoflagellate (Class Dinophyceae) nuclear ribosomal genes. In addition, there were only was only 1 to 3 publication per year before 2010 . From 2010 to 2019, the number of publications showed a noticeable upward trend, with increases since the year 2014 $(\mathrm{n}=59)$, reaching 987 publications in 2019.

Table 1. Number of published records per year.

\begin{tabular}{|c|c|}
\hline Year & Records, $\mathrm{n}$ \\
\hline 2001 & 1 \\
\hline 2002 & 0 \\
\hline 2003 & 2 \\
\hline 2004 & 0 \\
\hline 2005 & 1 \\
\hline 2006 & 1 \\
\hline 2007 & 1 \\
\hline 2008 & 2 \\
\hline 2009 & 2 \\
\hline 2010 & 3 \\
\hline 2011 & 10 \\
\hline 2012 & 21 \\
\hline 2013 & 35 \\
\hline 2014 & 59 \\
\hline 2015 & 127 \\
\hline 2016 & 225 \\
\hline 2017 & 406 \\
\hline 2018 & 722 \\
\hline 2019 & 989 \\
\hline Total & 2607 \\
\hline
\end{tabular}

Table 2. Percentage of published records by publication type.

\begin{tabular}{ll}
\hline Publication type & Records $(\mathrm{n}=2607), \mathrm{n}(\%)$ \\
\hline Article & $1858(71.27)$ \\
Meeting abstract & $388(14.84)$ \\
Review & $217(8.32)$ \\
Editorial material & $97(3.72)$ \\
Correction & $29(1.11)$ \\
Letter & $13(0.54)$ \\
News item & $5(0.19)$ \\
\hline
\end{tabular}

\section{Countries and Districts}

In total, 61 countries contributed to publications on single-cell sequencing technology worldwide. The results demonstrated that 7 countries published more than 100 records (Table 3), and the United States $(1454 / 2489,58.4 \%)$, with more than half of all identified records, published the most. The top 2 to 7 were
China (414/2489, 16.6\%), the United Kingdom (305/2489, $12.3 \%)$, Germany $(225 / 2489,9.0 \%)$, Sweden $(134 / 2489,5.4 \%)$, Japan (108/2489, 4.3\%), and Switzerland (104/2489, 4.2\%). Although the number of documents published by Australia, Canada, and the Netherlands was less than 100, no significant differences were observed $(P=.10)$, and the contribution was almost equal to that of Japan and Switzerland. In addition, the 
cooperation among studies in China was a little less than that in the United Kingdom. However, Sweden had the highest average number of citations (52.0 times), followed by Canada
(37.4 times), the United Kingdom (29.6 times), the United States (27.7 times), Australia (24.7 times), and Germany (23.9 times).

Table 3. Distribution by country.

\begin{tabular}{llllll}
\hline Rank & Country & Documents, $\mathrm{n}(\%)$ & Citations, $\mathrm{n}$ & Average citations & Total link strength \\
\hline 1 & USA & $1454(58.4)$ & 40337 & 27.7 & 549 \\
2 & China & $414(16.6)$ & 6537 & 15.8 & 206 \\
3 & UK & $305(12.3)$ & 9026 & 29.6 & 214 \\
4 & Germany & $225(9.0)$ & 5384 & 23.9 & 162 \\
5 & Sweden & $134(5.4)$ & 6973 & 52.0 & 88 \\
6 & Japan & $108(4.3)$ & 1454 & 13.5 & 68 \\
7 & Switzerland & $104(4.2)$ & 1802 & 17.3 & 72 \\
8 & Australia & $99(4.0)$ & 2442 & 24.7 & 70 \\
9 & Canada & $85(3.4)$ & 3177 & 37.4 & 15.7 \\
10 & Netherlands & $85(3.4)$ & 1330 & 53 \\
\hline
\end{tabular}

For the top 30 most prolific countries, which formed 6 clusters, a network map was created. There were active collaborations among these countries, especially between the United States and China (Figure 2A). From the dynamics and trends, it can be seen that the United States, China, Germany, Switzerland,
France, Australia, and the Netherlands have carried out studies on single-cell sequencing technology dating back to 2009. After 2015, many other investigators worldwide started to pay more attention to this field (Figure 2B).

Figure 2. Distribution of countries and regions. (A) The network map of countries (TOP30). (B) Dynamics and trends of countries/regions over years (TOP30).

A

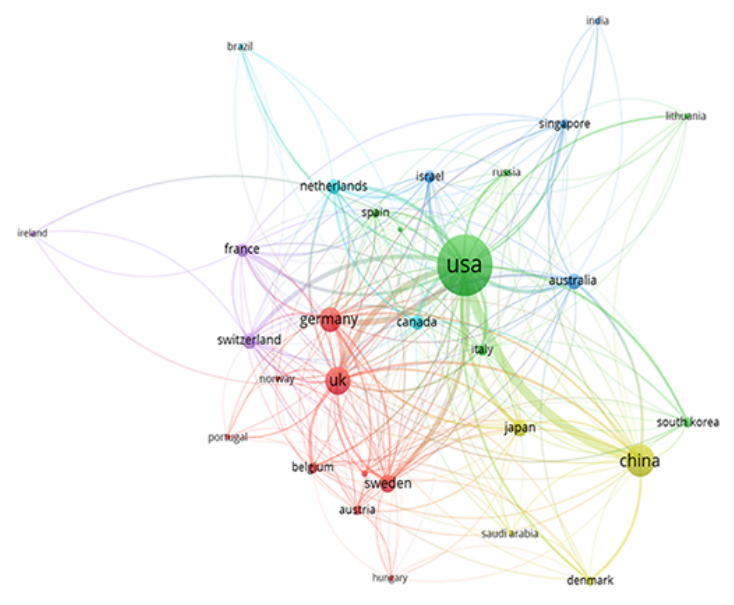

\section{Universities and Institutions}

A total of 1970 universities or institutions made contributions to single-cell sequencing technology; extensive cooperation network analysis was carried out among universities or institutions. In a network map and overlay visualization of institutions with the top 50 frequency, 5 clusters were formed (Figure 3A), and Harvard University ( $\mathrm{n}=226,9.1 \%$, Cluster 1), Stanford University $(\mathrm{n}=114,4.6 \%$, Cluster 5), Karolinska Institute ( $\mathrm{n}=111,4.5 \%$, Cluster 3$)$, Peking University $(\mathrm{n}=81$, $3.3 \%$, Cluster 4$)$, and the University of Washington $(n=77$, $3.1 \%$, Cluster 2) were the biggest nodes in every cluster,
B

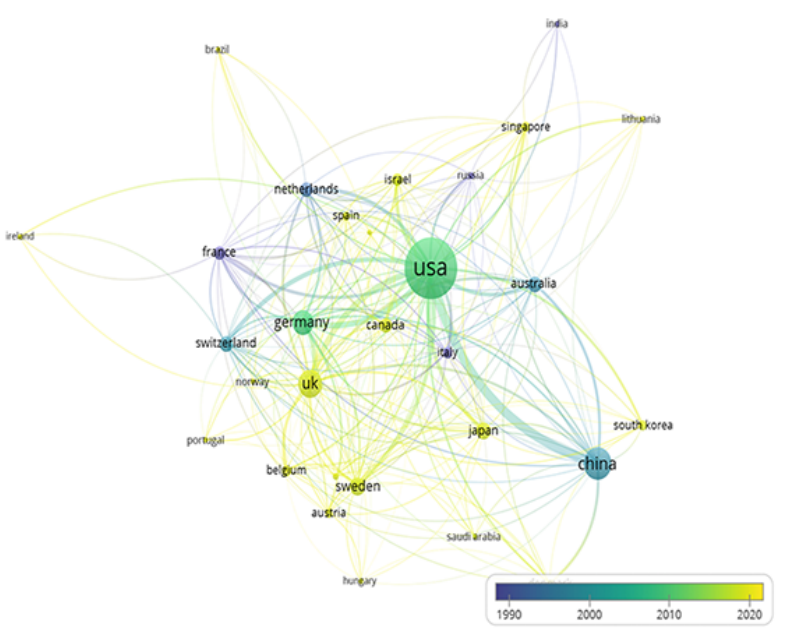

respectively. Cluster 1 was the biggest cluster, which contained 19 nodes that represented its related different universities or institutions, while Cluster 5 was the smallest, which included 3 nodes. The other clusters included 7 nodes (Cluster 2), 12 nodes (Cluster 3), and 9 nodes (Cluster 4). Furthermore, the results also showed that 4 universities contributed to primary and basic research on these topics earlier in time and started earlier on this field before 2010, which included Peking University, University of Melbourne, University of Penn, and the Tsinghua University. Since then, these studies have gradually gained popularity among other universities and institutes (Figure 3B). 
Figure 3. Distribution of universities and institutions. (A) The network map of universities and institutions (TOP50). (B) Dynamics and trends of universities and institutions over time (TOP50).

A

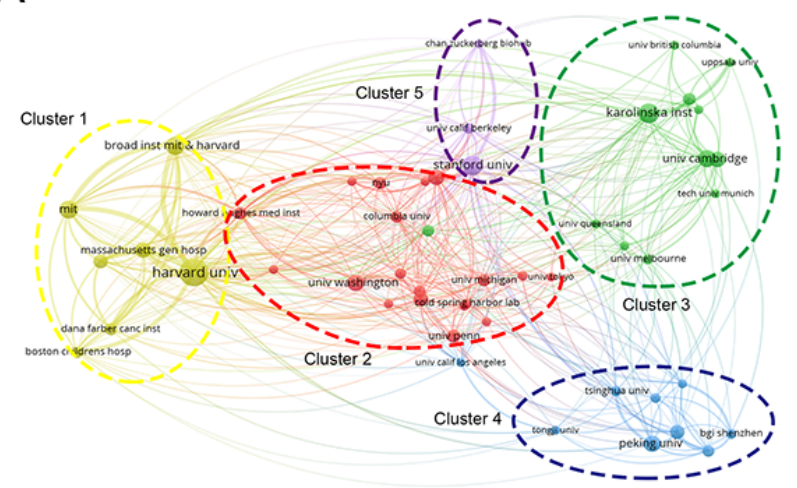

\section{Authors}

A total of 14,202 authors contributed to single-cell sequencing technology publications. The network map and overlay visualization of the top 200 cooperatively productive authors formed several clusters (Figure 4). Of these authors, 5 scientific teams contributed to most publications worldwide. The biggest 3 nodes were SA Teichmann (40/14,202, 1.6\%) and JC Marioni $38 / 14,202,1.5 \%$ ), who had the biggest cluster and were from
B

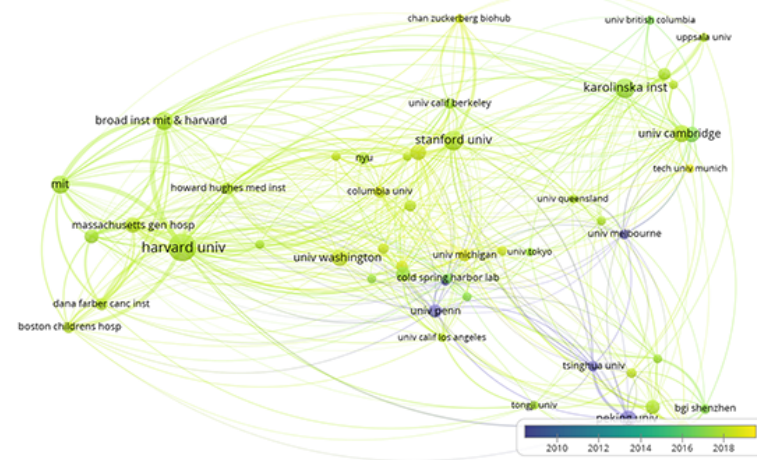

the University of Cambridge. In addition, A Regev (38/14,202, $1.5 \%$ ) had the second biggest cluster and was from Massachusetts Institute of Technology. The fourth node, FC Tang, represented a group from Peking University (26/14,202, $1.0 \%$ ), and 2 authors, $\mathrm{R}$ Sandberg and S Linnarsson from Sweden contributed to 49 records in total. Moreover, I Amit, from Israel, published 21 records to date (Multimedia Appendix $1)$.

Figure 4. Distribution of authors. (A) The network map of authors (TOP200). (B) Dynamics and trends of authors over time (TOP200).

A

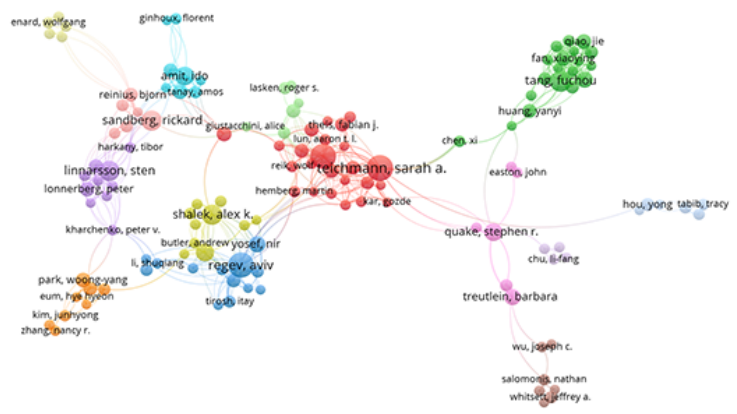

\section{Journals}

This study showed that a total of 495 journals published articles about single-cell sequencing technology. The results showed that the most productive journal was Nature Communications $(127 / 14,202,5.1 \%)$, the most cited journal was Nature Methods $(55 / 14,202,2.2 \%, 1764$ citation times in total), and the journal with the highest average citation was Nature Biotechnology $(28 / 14,202,1.1 \%$, average citation was 56.5 times). The top productive journals, top cited journals, and journals of top average citations are listed $(n=20)$ in Multimedia Appendix 2.
B

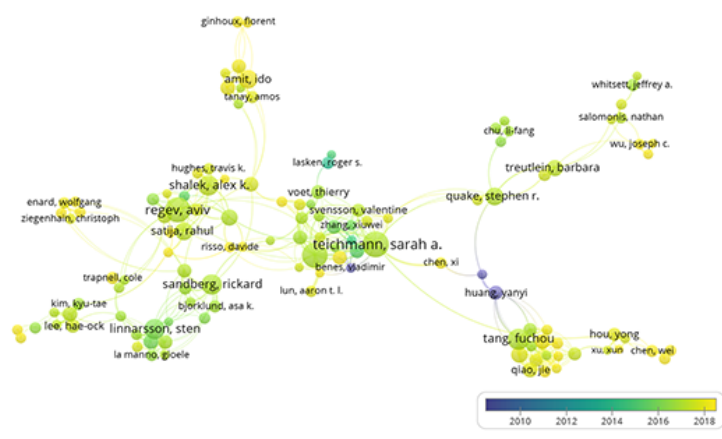

\section{Top 10 Citations of Included Records}

Of the 2489 papers, the top 10 publications ranked by citation are listed in Table 4. The first paper was published in the Journal of Computational Biology by A Bankevich et al in 2012 [27] and reported a new genome algorithm and its applications to single-cell sequencing, with 5668 citations, which was much higher than that of the second paper (1307 citations) [28]. Of the 10 records, 4 were published in Science, and the topics included intratumoral heterogeneity in primary glioblastoma [29], metastatic melanoma [30], and cell types in the mouse cortex and hippocampus revealed by single-cell RNA-sequencing [31]. The latest paper [30], which was published in 2016, has been cited 652 times (from 2016 to 2019). 
Table 4. Distribution by top 10-record co-citations.

\begin{tabular}{|c|c|c|c|c|}
\hline Rank & Top-cited record & Number of citations & Title & Journal \\
\hline 1 & $\begin{array}{l}\text { A Bankevich, } 2012 \\
\text { [27] }\end{array}$ & 5668 & $\begin{array}{l}\text { SPAdes: A New Genome Assembly Algorithm and Its Applica- } \\
\text { tions to Single-Cell Sequencing }\end{array}$ & $\begin{array}{l}\text { Journal of Computation- } \\
\text { al Biology }\end{array}$ \\
\hline 2 & N Navin, 2011 [28] & 1307 & Tumour evolution inferred by single-cell sequencing & Nature \\
\hline 3 & $\begin{array}{l}\text { AP Patel, } 2014 \\
\text { [29] }\end{array}$ & 1168 & $\begin{array}{l}\text { Single-cell RNA-seq highlights intratumoral heterogeneity in } \\
\text { primary glioblastoma }\end{array}$ & Science \\
\hline 4 & Y Peng, 2012 & 1039 & $\begin{array}{l}\text { IDBA-UD: a de novo assembler for single-cell and metagenomic } \\
\text { sequencing data with highly uneven depth }\end{array}$ & Bioinformatics \\
\hline 5 & A Zeisel, 2015 [31] & 923 & $\begin{array}{l}\text { Cell types in the mouse cortex and hippocampus revealed by } \\
\text { single-cell RNA-seq }\end{array}$ & Science \\
\hline 6 & C Trapnell, 2014 & 773 & $\begin{array}{l}\text { The dynamics and regulators of cell fate decisions are revealed } \\
\text { by pseudotemporal ordering of single cells }\end{array}$ & Nature Biotechnology \\
\hline 7 & S Picelli, 2014 & 734 & Full-length RNA-seq from single cells using Smart-seq2 & Nature Protocols \\
\hline 8 & I Tirosh, 2016 [30] & 652 & $\begin{array}{l}\text { Dissecting the multicellular ecosystem of metastatic melanoma } \\
\text { by single-cell RNA-seq }\end{array}$ & Science \\
\hline 9 & DA Jaitin, 2014 & 615 & $\begin{array}{l}\text { Massively Parallel Single-Cell RNA-Seq for Marker-Free Decom- } \\
\text { position of Tissues into Cell Types }\end{array}$ & Science \\
\hline 10 & R Satija, 2015 & 605 & Spatial reconstruction of single-cell gene expression data & Nature Biotechnology \\
\hline
\end{tabular}

\section{Co-citation References}

We used CiteSpace to visualize the co-citation network of references, which were divided into 11 co-citation clusters (Figure 5). The clusters were listed from 2008 to 2016: "transcriptional heterogeneity" (Cluster 10, n=4), "sequencing studies" (Cluster 0, $\mathrm{n}=53$ ), "high-throughput spatial mapping" (Cluster 13, n=3), "distal lung epithelium" (Cluster 1, n=37), "studying clonal evolution" (Cluster 3, n=33), "early embryo" (Cluster 7, n=9), "assembling single-cell genome" (Cluster 2, n=34), "high-throughput sequencing" (Cluster 4, n=27), "new genome assembly algorithm" (Cluster 8, $\mathrm{n}=7$ ), "genomic sequencing" (Cluster 5, n=14), and "future medical applications" (Cluster 6, n=13).

The top 36 references with the strongest citation bursts are presented in Multimedia Appendix 3. The first reference with a citation burst appeared in 2011, and most of the bursts appeared between 2011 and 2016. Only 1 reference [32] appears with a burst in the last 3 years.

Figure 5. The co-citation network of references.

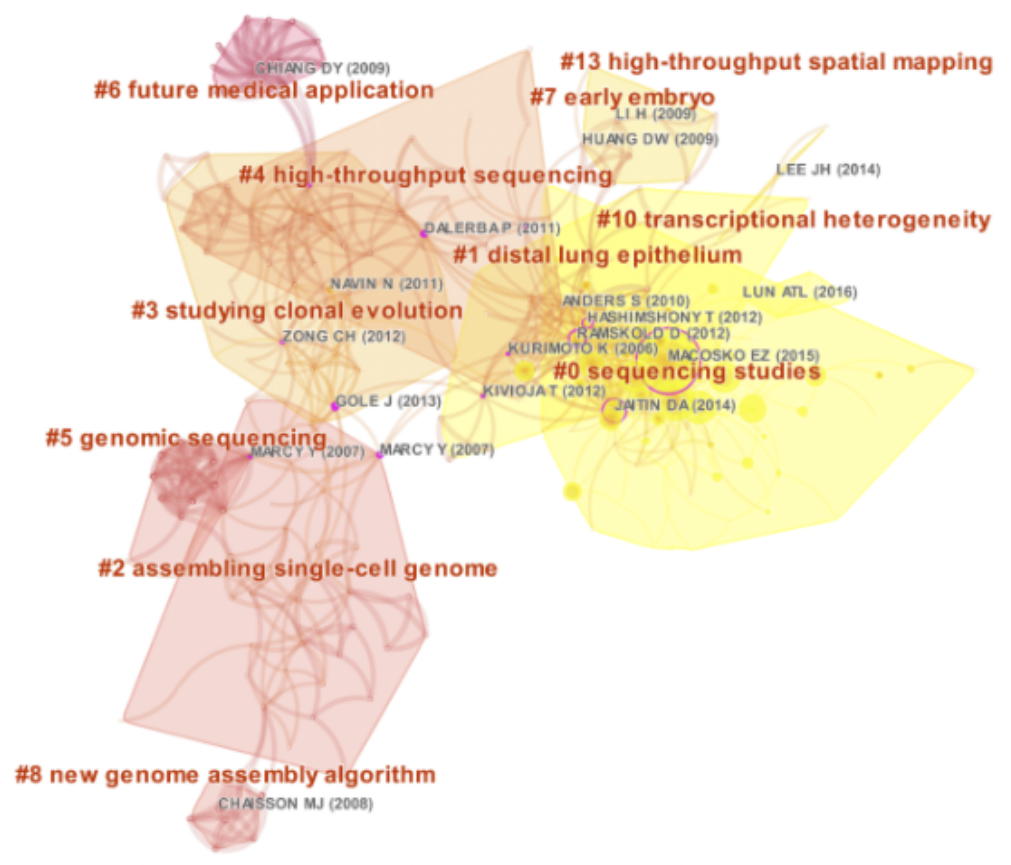




\section{Analysis of Keywords}

From the 2489 published records, a total of 6012 keywords were extracted. The network map of the top 100 frequency keywords was clustered and formed 4 clusters (Figure 6A), and the biggest 3 nodes were "gene-expression," "RNA-seq," and "heterogeneity." Moreover, the overlay visualization of the top 100 frequency keywords between 2001 and 2020 is shown in Figure 6B.

Cluster 1, with the biggest node "gene-expression," represented the primary research points of single-cell sequencing, such as stem cells, self-renewal, progenitors, lineage, differentiation, protein and identification, which might be based upon next generation sequencing and single cell isolation methods. Cluster 2 represented improvements in computer algorithms for sequencing data and advancements in single-cell sequencing methods, for instance, keywords such as heterogeneity, transcriptome, RNA-sequencing data, dynamics, noise, and normalization, especially, the stem cells of embryos might be paid more attention to in this cluster. Cluster 3, considered as the currently being developed field in this topic, and could be named the research hotspots of single-cell sequencing. Moreover, the biggest node of Cluster 3 was marked as cancer, which was related to many keywords, including circulating tumor-cells, origin, evolution, landscape, metastasis, resistance, and progression. In addition, it was also indicated that these topics on breast cancer might stay in a leading position and published more papers. Regarding the future direction of single-cell sequencing technology, Cluster 4 was entitled developmental trends of immunology in single-cell sequencing, and keywords included dendritic cells, T-cells, macrophages, and diversity, which might be related to tumor survival, neuronal growth, and activation of regulators. Moreover, the results in Figure 6B showed that the biggest nodes, such as "gene-expression," "RNA-seq," and "heterogeneity," emerged around the year 2005. Subsequently, the frequency of many keywords, including "single-cell," "noise," "seq," and "gene" gradually increased after 2010 and rapidly gained interest from 2015 to 2020 .

The data showed that all keywords with citation bursts first appeared in 2001 (Multimedia Appendix 4). Similarly, breast cancer was a primary research hotspot from 2011 to 2017. Furthermore, at the beginning of 2013, many keywords related to computer algorithms, such as "noise" and "evolution," displayed the strongest citation bursts. Regarding the keyword single-cell sequencing, the time-period of the strongest citation bursts was from 2015 to 2017.

Figure 6. Distribution of 100 frequency keywords. (A) Network map of the frequency keywords(TOP100). (B) Dynamics and trends of the frequency keywords over times(TOP100).

A

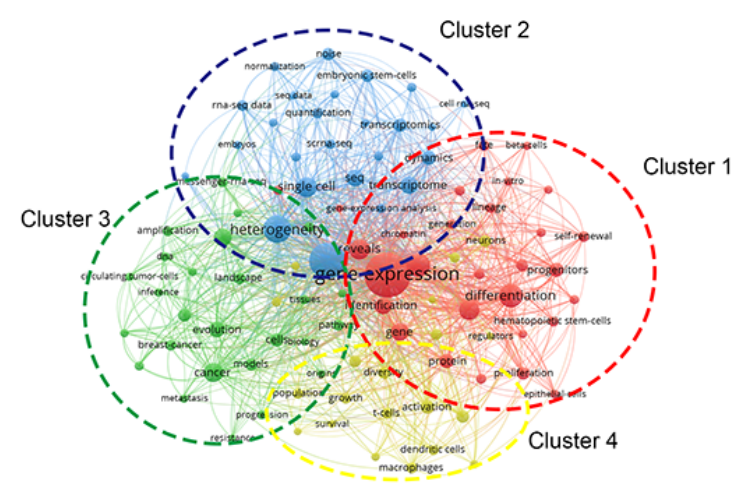

Table 5 summarizes occurrence and the total link strength of the top 30 keywords. Higher keyword occurrences indicated the primary research hotspot was single-cell sequencing applications, including "heterogeneity," "differentiation," "genome," and "transcriptome" of "single cells," which mainly
B

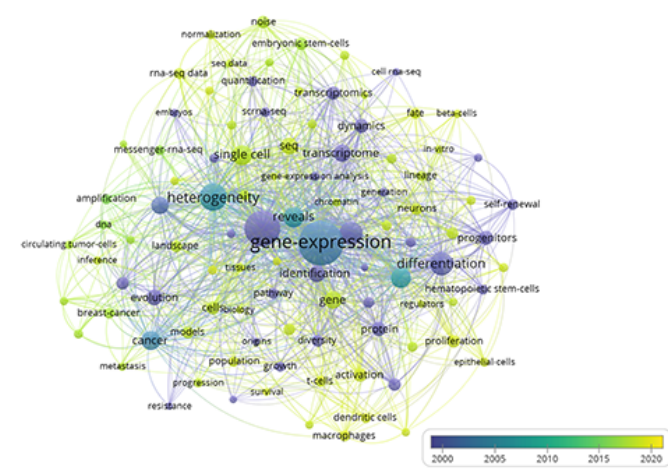

covers the field of stem cells, such as embryonic stem cells, and the field of cancer. Furthermore, the dynamics, landscape, and diversity of single cells maintained their popularity and showed a stronger total link strength among these 30 keywords. 
Table 5. Occurrences and total link strength of top 30 keywords.

\begin{tabular}{|c|c|c|c|}
\hline Rank & Keyword & Occurrences & Total link strength \\
\hline 1 & Gene-expression & 857 & 851 \\
\hline 2 & RNA-seq & 563 & 559 \\
\hline 3 & Heterogeneity & 331 & 325 \\
\hline 4 & Stem-cells & 235 & 234 \\
\hline 5 & Differentiation & 231 & 231 \\
\hline 6 & Single cell & 177 & 177 \\
\hline 7 & Reveals & 170 & 170 \\
\hline 8 & Cancer & 155 & 154 \\
\hline 9 & Transcriptome & 135 & 135 \\
\hline 10 & Gene & 133 & 132 \\
\hline 11 & Mouse & 133 & 132 \\
\hline 12 & Genome & 132 & 130 \\
\hline 13 & Identification & 125 & 125 \\
\hline 14 & Seq & 125 & 122 \\
\hline 15 & Evolution & 115 & 115 \\
\hline 16 & Progenitors & 93 & 93 \\
\hline 17 & Protein & 92 & 92 \\
\hline 18 & Dynamics & 90 & 90 \\
\hline 19 & Activation & 83 & 83 \\
\hline 20 & Transcriptomics & 80 & 78 \\
\hline 21 & Cells & 77 & 77 \\
\hline 22 & Receptors & 73 & 73 \\
\hline 23 & Noise & 70 & 70 \\
\hline 24 & Mutations & 69 & 69 \\
\hline 25 & Proliferation & 67 & 67 \\
\hline 26 & Embryonic Stem-cells & 66 & 66 \\
\hline 27 & Landscape & 65 & 65 \\
\hline 28 & Neurons & 65 & 65 \\
\hline 29 & Models & 64 & 64 \\
\hline 30 & Diversity & 63 & 63 \\
\hline
\end{tabular}

\section{Discussion}

\section{Principal Results}

In this study, we summarized research collaborations, new development, and research trends of single-cell sequencing worldwide. In particular, bibliometric analysis offers a new possibility of visualizing current hotpots and trends in this field based on the information of published records $[19,20]$. We were able to analyze the most productive authors and institutions, by journal and by co-citation references, and we illustrated the different research groups of authors with collaboration networks in the past two decades. In total, 2489 records were identified, published in 495 journals by 14,202 authors from 1970 institutes in 61 countries. The United States had the highest absolute productivity ranking, followed by China and Japan (East Asia), the United Kingdom, Germany, other European countries (Sweden, Switzerland, the Netherlands), and Australia and Canada. Taken together, these results indicated that single-cell sequencing technology developed rapidly and spread globally in the past 5 years (after 2015), which might be influenced by the amount of funding available for single-cell sequencing projects in each country. $\mathrm{Li}$ et al [33] investigated the distribution and development of single-cell sequencing in China, the United Kingdom, and the United States, focusing on government support, and concluded that there was a gap between high-income and low-income countries with respect to the amount of funding and number of projects. When compared with China, the amount of funding and the number of projects for single-cell sequencing in the United States and the United Kingdom had increased dramatically before 2016 (915 projects, 
cumulative funding of US \$539 million). On the other hand, the later the starting time of foundation support for studies on single-cell sequencing, the less applications of this technology.

After the first record on single-cell sequencing, on the nuclear ribosomal genes of dinoflagellate (Dinophyceae), was published in 2001 [26], the number of publications was sporadic (1 to 3 annually until 2010). With the advancement of high-throughput sequencing and new computer algorithms, the development trend of publications changed from 2010 to 2019, showing a clear upward trend since 2014. However, as the development of single-cell sequencing technology has lasted for almost 20 years, several studies represent basic milestones of single-cell sequencing [2]. For example, the advancement of next-generation sequencing platforms in 2005 [34] offered a better approach for primary single-cell sequencing for isolated single cells. Subsequently, Tang et al [6] were the first to introduce RNA transcriptome sequencing of a mammalian cell in 2009, and Navin et al [28] published the first genomic sequencing of single human cells in 2011. Furthermore, several representative papers were published in the subsequent 3 years, including not only exome single-cell DNA sequencing [35] and its related single-cell DNA sequencing of sperm cells [36], neurons [37], circulating tumor cells [38], and the microbial tree [39], but also, the first single-cell sequencing of the RNA of immune cells [40] and of epigenomes [41]. Certainly, single-cell sequencing methods have supported advances in other technologies, including multiomics sequencing [8]; methods have led to novel discoveries in many scientific fields, such as tumor research [9], microbiology [10], neurology $[11,12]$, reproduction [13], and immunology [14], which could explain the recent exponential increase in the number of publications.

While the United States published the most records worldwide (1454/2489, 58.42\%), Sweden had the highest citation average (52.04 times). Citations differed from the number of documents, as did the cooperation of countries and regions: United States, China, United Kingdom, and Germany showed the strongest cooperation, with higher total link strengths. This was mainly because studies on single-cell sequencing technology were published earlier in these countries, which was indicated by the dynamics and trends of countries and regions over the years (Figure 3B). We believe that publications from Sweden had deeper impacts on the single-cell sequencing technology, although the field seems to be small and young enough that most of the findings can be entirely due to individual pioneering researchers. Furthermore, we also found that Karolinska Institutes, from Sweden, was one of the biggest nodes in its cluster of collaboration network (Figure 4A; Cluster 3), which might provide an indirect explanation. Similarly, the analysis of institutions and authors almost matched the distribution by countries and districts. Of the 1970 universities or institutions, the institutes from United States (Harvard University, Stanford University, University of Washington, and University of Penn), European universities (Karolinska Institute and Cambridge University), and Chinese institutes (Peking University and Tsinghua University), as well as the University of Melbourne in Australia, have taken leading places in single-cell sequencing technology, with steady collaborations in global groups.
Moreover, of the 14,202 authors who contributed to publications, the top 200 authors were situated in the collaboration networks that account for large proportions of research, mainly from the above-mentioned countries and institutes.

Single-cell sequencing avoids the drawbacks of bulk experiments, which only demonstrate average gene expression, and it can be used to study real differences and evolutionary changes in single cells [7]; therefore, it has gained the popularity and interest of the editors of many journals. Of the 495 journals, 20 journals contributed the most. The top journals were Nature Communications (most papers with 127 papers), Nature Methods (most cited with 1764 citations), and Nature Biotechnology (highest average citations with 56.46 citations per paper). Moreover, of included records, all the top 10 most cited papers were published in the top journals. In addition, the research topics of these top-cited records reported or introduced a new genome algorithm and application of single-cell sequencing [27-31], which together have been cited more than 600 times in the past of 5 years. In co-citation analysis, knowledge on "clonal evolution," "early embryo," "assembling single-cell genome," "high-throughput sequencing," and "new genome assembly algorithm" were the basis of single-cell sequencing research, and most references with citation bursts appeared between 2011 and 2016.

Of 4 clusters in visualization maps to explore key topics and future directions, Cluster 1 represented the basis of single-cell sequencing (next generation sequencing and single cell isolation methods researched earlier), while Cluster 2 represented the development of computer methods and algorithms. Cluster 3 showed current research hotspots of single-cell sequencing, such as applications in cancer research, with keywords including, circulating tumor-cells, origin, evolution, landscape, metastasis, resistance, and progression, and Cluster 4 showed that immunology will be the next hotspot of single-cell sequencing technology research, with keywords including dendritic cells, t-cells, macrophages, and diversity. In particular, in immunology, neuronal growth and the activation of regulators have been studied in recent years, rapidly gaining interest from 2015 to 2020 .

\section{Limitations}

Our study had several limitations. First, we only searched records from the WoSCC and only included records in English, which might result in selection bias. However, the number of included records in our study was large enough to represent the current evidence landscape of single-cell sequencing technology [42]. Second, although the data had been manually standardized, bias might still exist due to the authors with the same name or the keywords of various expressions. Third, by using software, we might have overlooked some information, which may result in errors in data analysis, even if there are some reasonable and unavoidable differences on the same outcomes between CiteSpace and VOSviewer. This was the first study to perform bibliometric analysis on single-cell sequencing technology research, to identify collaboration networks among authors, countries, and institutions and illustrate developmental trends, current hotspots, and future directions in this field. 


\section{Recommendations for Future Work}

Single-cell sequencing methods have addressed the drawbacks of averaged gene expression in bulk experiments and provide a possible approach to understanding biological diversity and rare cells. Over the past 10 years, the applications have had a broad impact in many fields, which emerged as delineating cell diversity, tracing cell lineages, classifying cell types, and profiling rare cells [2]. We only selected publications related to immunotherapy in the entire year of 2019, to form and label clusters (Multimedia Appendix 5). Eventually, the formed clusters illustrated that current hotspots in immunology involve at least 5 topics. Cancer immunotherapy is an exciting topic, for which single-cell sequencing methods have great potential for investigating the heterogeneity of intratumor immunity and other topics such as immune cell involvement of breast cancer therapy, role of immune cells in nervous system, formation and differentiation of immune cells, and functions of immune cells in the tumor microenvironment. Cancer therapy research to clarifying the functions of T-cells and macrophages, understand the antigenicity in intratumor heterogeneity, and study the role of clonal diversity in transformation, invasion, and evolution of chemoresistance would open new avenues for preventing cancer in the future. Cancer immunotherapy has revolutionized cancer treatment, and a detailed immune cell atlas at single-cell resolution could facilitate a comprehensive understanding the immunity landscape in tumor microenvironments [43] Moreover, future efforts in the development of single-cell sequencing technology will also emerge, which could focus on single-cell multimodal omics, such as genomic DNA-messenger RNA sequencing [44,45], genome and transcriptome sequencing [46], and single-cell methylome and transcriptome sequencing [47]. Currently, the areas of particular relevance to immuno-oncology based upon single-cell sequencing technology focus on the ability to track individual specific cell clones through paired sequencing of their cell receptor genes and high-dimensional single-cell spatial analysis [48]. High-dimensional single-cell sequencing technologies are likely to generate clinically relevant biomarker signatures in immuno-oncology and may be able to guide clinical decision making.

\section{Conclusions}

The number of publications related to single-cell sequencing technology has increased dramatically since 2014. The United States led absolute productivity ranks by contributing approximately $60 \%$ of the total publications, followed by China, the United Kingdom, and Germany. Similarly, collaboration networks consisted mainly of institutes and authors from the above-mentioned countries. Moreover, in terms of the top 10 productive journals, the most cited journals, and journals with the highest average citation, there were 20 journals calculated in total. And most of them were considered as top-journals (impact factor $>10, \mathrm{Q} 1$ ).Single-cell sequencing technology has made a large impact in various fields of biology, with a noticeable increase in publications annually in the last 5 years. We believe that the field of immunology might be a future research hotspot.

\section{Acknowledgments}

We thank MogoEdit, a professional copyediting agency, for helping to improve the quality of language in our manuscript. This work was supported by National Key Research and Development Program of China (2017YFC1308805), Industry-University-Research Innovation Fund in Ministry of Education of the People's Republic of China (2018A01013) and National Natural Science Foundation of China (grant 81871962).

\section{Authors' Contributions}

QW, KLY, ZZ, SW, and KWJ designed the study. KLY and ZW searched the database using the search strategy from JHT and LL. QW, ZW, KWJ, KLY, ZZ, and YJY screened the titles and abstracts to select articles. KLY, ZW, and YJY conducted analysis and mapping. All authors participated in the interpretation of the results. QW, KLY, SW, and KWJ wrote the manuscript with input from all authors. All authors read and approved the final manuscript.

\section{Conflicts of Interest}

None declared.

\section{Multimedia Appendix 1}

Distribution of top 10 productive authors. [DOCX File , 15 KB-Multimedia Appendix 1]

\section{Multimedia Appendix 2}

Distribution by top journals and its citations. [DOCX File, 17 KB-Multimedia Appendix 2]

\section{Multimedia Appendix 3}

Top 36 references with strongest citation bursts. [PNG File , 438 KB-Multimedia Appendix 3] 


\section{Multimedia Appendix 4}

Top 15 keywords with the strongest citation bursts.

[PNG File, 72 KB-Multimedia Appendix 4]

\section{Multimedia Appendix 5}

Clusters of immunotherapy in 2019.

[PNG File , 677 KB-Multimedia Appendix 5]

\section{References}

1. Bianconi E, Piovesan A, Facchin F, Beraudi A, Casadei R, Frabetti F, et al. An estimation of the number of cells in the human body. Ann Hum Biol 2013;40(6):463-471. [doi: 10.3109/03014460.2013.807878] [Medline: 23829164]

2. Wang Y, Navin NE. Advances and applications of single-cell sequencing technologies. Mol Cell 2015;58(4):598-609 [FREE Full text] [doi: 10.1016/j.molcel.2015.05.005] [Medline: 26000845]

3. Tang X, Huang Y, Lei J, Luo H, Zhu X. The single-cell sequencing: new developments and medical applications. Cell Biosci 2019;9:53 [FREE Full text] [doi: 10.1186/s13578-019-0314-y] [Medline: 31391919]

4. Wen L, Tang F. Boosting the power of single-cell analysis. Nat Biotechnol 2018;36(5):408-409. [doi: 10.1038/nbt.4131] [Medline: 29734314]

5. Stegle O, Teichmann SA, Marioni JC. Computational and analytical challenges in single-cell transcriptomics. Nat Rev Genet 2015;16(3):133-145. [doi: 10.1038/nrg3833] [Medline: 25628217]

6. Tang F, Barbacioru C, Wang Y, Nordman E, Lee C, Xu N, et al. mRNA-Seq whole-transcriptome analysis of a single cell. Nat Methods 2009;6(5):377-382. [doi: 10.1038/nmeth.1315] [Medline: 19349980]

7. Dal Molin A, Di Camillo B. How to design a single-cell RNA-sequencing experiment: pitfalls, challenges and perspectives. Brief Bioinform 2019;20(4):1384-1394. [doi: 10.1093/bib/bby007] [Medline: 29394315]

8. Li J, Lin H, Hou R, Shen J, Li X, Xing J, et al. Multi-omics study in monozygotic twins confirm the contribution of de novo mutation to psoriasis. J Autoimmun 2020;106:102349 [FREE Full text] [doi: 10.1016/j.jaut.2019.102349] [Medline: $\underline{31629629]}$

9. Zhang Q, He Y, Luo N, Patel SJ, Han Y, Gao R, et al. Landscape and dynamics of single immune cells in hepatocellular carcinoma. Cell 2019 Oct 31;179(4):829-845.e20 [FREE Full text] [doi: 10.1016/j.cell.2019.10.003] [Medline: 31675496]

10. Wang Y, Niu Q, Zhang X, Liu L, Wang Y, Chen Y, et al. Exploring the effects of operational mode and microbial interactions on bacterial community assembly in a one-stage partial-nitritation anammox reactor using integrated multiomics. Microbiome 2019;7(1):122 [FREE Full text] [doi: 10.1186/s40168-019-0730-6] [Medline: $\underline{31462278]}$

11. Lake BB, Chen S, Sos BC, Fan J, Kaeser GE, Yung YC, et al. Integrative single-cell analysis of transcriptional and epigenetic states in the human adult brain. Nat Biotechnol 2018;36(1):70-80 [FREE Full text] [doi: 10.1038/nbt.4038] [Medline: 29227469]

12. Rosenberg AB, Roco CM, Muscat RA, Kuchina A, Sample P, Yao Z, et al. Single-cell profiling of the developing mouse brain and spinal cord with split-pool barcoding. Science 2018;360(6385):176-182 [FREE Full text] [doi:

10.1126/science.aam8999] [Medline: 29545511]

13. Guo F, Li L, Li J, Wu X, Hu B, Zhu P, et al. Single-cell multi-omics sequencing of mouse early embryos and embryonic stem cells. Cell Res 2017;27(8):967-988 [FREE Full text] [doi: 10.1038/cr.2017.82] [Medline: 28621329]

14. Casasent AK, Schalck A, Gao R, Sei E, Long A, Pangburn W, et al. Multiclonal invasion in breast tumors identified by topographic single cell sequencing. Cell 2018;172(1-2):205-217 [FREE Full text] [doi: 10.1016/j.cell.2017.12.007] [Medline: 29307488]

15. Suvà ML, Tirosh I. Single-cell RNA sequencing in cancer: lessons learned and emerging challenges. Mol Cell 2019;75(1):7-12 [FREE Full text] [doi: 10.1016/j.molcel.2019.05.003] [Medline: 31299208]

16. Zhang X, Liu L. Applications of single cell RNA sequencing to research of stem cells. World J Stem Cells 2019;11(10):722-728 [FREE Full text] [doi: 10.4252/wjsc.v11.i10.722] [Medline: 31692946]

17. Ren X, Kang B, Zhang Z. Understanding tumor ecosystems by single-cell sequencing: promises and limitations. Genome Biol 2018;19(1):211 [FREE Full text] [doi: 10.1186/s13059-018-1593-z] [Medline: 30509292]

18. Kiselev VY, Andrews TS, Hemberg M. Challenges in unsupervised clustering of single-cell RNA-seq data. Nat Rev Genet 2019 May;20(5):273-282. [doi: 10.1038/s41576-018-0088-9] [Medline: 30617341]

19. Agarwal A, Durairajanayagam D, Tatagari S, Esteves SC, Harlev A, Henkel R, et al. Bibliometrics: tracking research impact by selecting the appropriate metrics. Asian J Androl 2016;18(2):296-309 [FREE Full text] [doi: 10.4103/1008-682X.171582] [Medline: 26806079]

20. Keathley-Herring H, Van Aken E, Gonzalez-Aleu F, Deschamps F, Letens G, Orlandini PC. Assessing the maturity of a research area: bibliometric review and proposed framework. Scientometrics 2016 Aug 13;109(2):927-951. [doi: 10.1007/s11192-016-2096-x]

21. Chen C. CiteSpace II: detecting and visualizing emerging trends and transient patterns in scientific literature. J Am Soc Inf Sci 2006 Feb 01;57(3):359-377. [doi: 10.1002/asi.20317] 
22. van Eck NJ, Waltman L. Citation-based clustering of publications using CitNetExplorer and VOSviewer. Scientometrics 2017;111(2):1053-1070 [FREE Full text] [doi: 10.1007/s11192-017-2300-7] [Medline: 28490825]

23. Devos P, Ménard J. Trends in worldwide research in hypertension over the period 1999-2018: a bibliometric study. Hypertension 2020;76(5):1649-1655 [FREE Full text] [doi: 10.1161/HYPERTENSIONAHA.120.15711] [Medline: $\underline{32862706}$ ]

24. van Eck NJ, Waltman L. Software survey: VOSviewer, a computer program for bibliometric mapping. Scientometrics 2010 Aug;84(2):523-538 [FREE Full text] [doi: 10.1007/s11192-009-0146-3] [Medline: 20585380]

25. van Eck NJ, Waltman L. Text mining and visualization using VOSviewer. Arxiv 2011 Sep 09 [FREE Full text]

26. Ruiz Sebastián C, O'Ryan C. Single-cell sequencing of dinoflagellate (Dinophyceae) nuclear ribosomal genes. Mol Ecol Notes 2001;1(4):329-331. [doi: 10.1046/j.1471-8278.2001.00084.x]

27. Bankevich A, Nurk S, Antipov D, Gurevich AA, Dvorkin M, Kulikov AS, et al. SPAdes: a new genome assembly algorithm and its applications to single-cell sequencing. J Comput Biol 2012;19(5):455-477 [FREE Full text] [doi: 10.1089/cmb.2012.0021] [Medline: 22506599]

28. Navin N, Kendall J, Troge J, Andrews P, Rodgers L, McIndoo J, et al. Tumour evolution inferred by single-cell sequencing. Nature 2011;472(7341):90-94 [FREE Full text] [doi: 10.1038/nature09807] [Medline: 21399628]

29. Patel AP, Tirosh I, Trombetta JJ, Shalek AK, Gillespie SM, Wakimoto H, et al. Single-cell RNA-seq highlights intratumoral heterogeneity in primary glioblastoma. Science 2014;344(6190):1396-1401 [FREE Full text] [doi: 10.1126/science.1254257] [Medline: 24925914]

30. Tirosh I, Izar B, Prakadan SM, Wadsworth MH, Treacy D, Trombetta JJ, et al. Dissecting the multicellular ecosystem of metastatic melanoma by single-cell RNA-seq. Science 2016;352(6282):189-196 [FREE Full text] [doi: 10.1126/science.aad0501] [Medline: 27124452]

31. Zeisel A, Muñoz-Manchado AB, Codeluppi S, Lönnerberg P, La Manno G, Juréus A, et al. Brain structure. cell types in the mouse cortex and hippocampus revealed by single-cell RNA-seq. Science 2015;347(6226):1138-1142 [FREE Full text] [doi: 10.1126/science.aaa1934] [Medline: 25700174]

32. Kolodziejczyk AA, Kim JK, Svensson V, Marioni JC, Teichmann SA. The technology and biology of single-cell RNA sequencing. Mol Cell 2015;58(4):610-620 [FREE Full text] [doi: 10.1016/j.molcel.2015.04.005] [Medline: 26000846]

33. Li A, Tang X. Foundation support for studies on single-cell sequencingits application in USA, Britain and China. Chin J Med Lib Info Sci 2017;26(7):44-51. [doi: 10.3969/j.issn.1671-3982.2017.09.008]

34. Metzker ML. Emerging technologies in DNA sequencing. Genome Res 2005;15(12):1767-1776 [FREE Full text] [doi: $\underline{10.1101 / g r .3770505]}$ [Medline: 16339375$]$

35. Xu X, Hou Y, Yin X, Bao L, Tang A, Song L, et al. Single-cell exome sequencing reveals single-nucleotide mutation characteristics of a kidney tumor. Cell 2012;148(5):886-895 [FREE Full text] [doi: 10.1016/j.cell.2012.02.025] [Medline: $22385958]$

36. Wang J, Fan HC, Behr B, Quake SR. Genome-wide single-cell analysis of recombination activity and de novo mutation rates in human sperm. Cell 2012;150(2):402-412 [FREE Full text] [doi: 10.1016/j.cell.2012.06.030] [Medline: 22817899]

37. Evrony GD, Cai X, Lee E, Hills LB, Elhosary PC, Lehmann HS, et al. Single-neuron sequencing analysis of L1 retrotransposition and somatic mutation in the human brain. Cell 2012;151(3):483-496 [FREE Full text] [doi: 10.1016/j.cell.2012.09.035] [Medline: 23101622]

38. Ramsköld D, Luo S, Wang Y, Li R, Deng Q, Faridani OR, et al. Full-length mRNA-seq from single-cell levels of RNA and individual circulating tumor cells. Nat Biotechnol 2012;30(8):777-782 [FREE Full text] [doi: 10.1038/nbt.2282] [Medline: 22820318]

39. Rinke C, Schwientek P, Sczyrba A, Ivanova NN, Anderson IJ, Cheng J, et al. Insights into the phylogeny and coding potential of microbial dark matter. Nature 2013;499(7459):431-437. [doi: 10.1038/nature12352] [Medline: 23851394]

40. Shalek AK, Satija R, Adiconis X, Gertner RS, Gaublomme JT, Raychowdhury R, et al. Single-cell transcriptomics reveals bimodality in expression and splicing in immune cells. Nature 2013;498(7453):236-240 [FREE Full text] [doi: 10.1038/nature12172] [Medline: 23685454]

41. Nagano T, Lubling Y, Stevens TJ, Schoenfelder S, Yaffe E, Dean W, et al. Single-cell Hi-C reveals cell-to-cell variability in chromosome structure. Nature 2013;502(7469):59-64 [FREE Full text] [doi: 10.1038/nature12593] [Medline: 24067610]

42. Peng C, He M, Cutrona SL, Kiefe CI, Liu F, Wang Z. Theme trends and knowledge structure on mobile health apps: bibliometric analysis. JMIR Mhealth Uhealth 2020;8(7):e18212 [FREE Full text] [doi: 10.2196/18212] [Medline: 32716312]

43. Zheng Y, Chen Z, Han Y, Han L, Zou X, Zhou B, et al. Immune suppressive landscape in the human esophageal squamous cell carcinoma microenvironment. Nat Commun 2020;11(1):6268 [FREE Full text] [doi: 10.1038/s41467-020-20019-0] [Medline: $\underline{3293583}$ ]

44. Zhu C, Preissl S, Ren B. Single-cell multimodal omics: the power of many. Nat Methods 2020;17(1):11-14. [doi: 10.1038/s41592-019-0691-5] [Medline: 31907462]

45. Dey SS, Kester L, Spanjaard B, Bienko M, van Oudenaarden A. Integrated genome and transcriptome sequencing of the same cell. Nat Biotechnol 2015;33(3):285-289 [FREE Full text] [doi: 10.1038/nbt.3129] [Medline: 25599178]

46. Macaulay IC, Haerty W, Kumar P, Li YI, Hu TX, Teng MJ, et al. Nat Methods 2015;12(6):519-522. [doi: 10.1038/nmeth.3370] [Medline: 25915121] 
47. Angermueller C, Clark SJ, Lee HJ, Macaulay IC, Teng MJ, Hu TX, et al. Parallel single-cell sequencing links transcriptional and epigenetic heterogeneity. Nat Methods 2016;13(3):229-232 [FREE Full text] [doi: 10.1038/nmeth.3728] [Medline: 26752769]

48. Gohil SH, Iorgulescu JB, Braun DA, Keskin DB, Livak KJ. Applying high-dimensional single-cell technologies to the analysis of cancer immunotherapy. Nat Rev Clin Oncol 2021 Apr;18(4):244-256. [doi: 10.1038/s41571-020-00449-x] [Medline: $\underline{3277626}$ ]

\section{Abbreviations}

WoSCC: Web of Science Core Collection

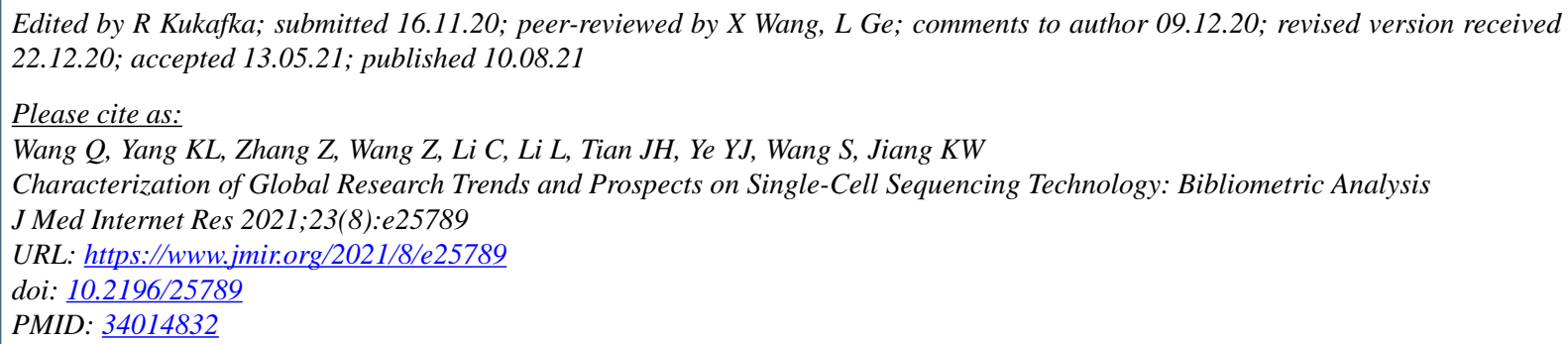

(CQuan Wang, Ke-Lu Yang, Zhen Zhang, Zhu Wang, Chen Li, Lun Li, Jin-Hui Tian, Ying-Jiang Ye, Shan Wang, Ke-Wei Jiang. Originally published in the Journal of Medical Internet Research (https://www.jmir.org), 10.08.2021. This is an open-access article distributed under the terms of the Creative Commons Attribution License (https://creativecommons.org/licenses/by/4.0/), which permits unrestricted use, distribution, and reproduction in any medium, provided the original work, first published in the Journal of Medical Internet Research, is properly cited. The complete bibliographic information, a link to the original publication on https://www.jmir.org/, as well as this copyright and license information must be included. 